\title{
Primary central nervous system angiosarcoma: two case reports
}

\author{
James R Hackney ${ }^{1}$, Cheryl Ann Palmer ${ }^{1,2^{*}}$, Kristen O Riley ${ }^{3}$, Joel K Cure ${ }^{4}$, Hassan M Fathallah-Shaykh ${ }^{2}$ \\ and Louis B Nabors ${ }^{2}$
}

\begin{abstract}
Introduction: Primary angiosarcoma of the brain is extremely rare; only 15 cases have been reported in adults over the last 25 years.

Case presentations: We describe two cases of primary angiosarcoma of the brain that are well characterized by imaging, histopathology, and immunohistochemistry. Case 1: our first patient was a 35-year-old woman who developed exophthalmos. Subtotal resection of a left extra-axial retro-orbital mass was performed. Case 2: our second patient was a 47-year-old man who presented to our facility with acute visual loss, word-finding difficulty and subtle memory loss. A heterogeneously-enhancing left sphenoid wing mass was removed. We also review the literature aiming at developing a rational approach to diagnosis and treatment, given the rarity of this entity.

Conclusions: Gross total resection is the standard of care for primary angiosarcoma of the brain. Adjuvant radiation and chemotherapy are playing increasingly recognized roles in the therapy of these rare tumors.
\end{abstract}

Keywords: Angiosarcoma, Primary Central Nervous System (CNS) Tumors, Sarcoma, Bevacizumab, Temozolomide

\section{Introduction}

Primary angiosarcoma of the central nervous system (CNS) is an extremely rare malignancy, with only approximately 15 cases reported in adults in the literature over the last 25 years. Mena et al. [1] contributed six cases in adults, the total number of cases from the files of the Armed Forces Institutes of Pathology (AFIP) between 1970 to 1987. Merimsky et al. [2] reported a small series of CNS sarcomas that included three angiosarcomas, while Paulus et al. [3] also reported a slightly larger series of primary intra-cranial sarcomas that included two angiosarcomas. The remaining cases derive from single case reports [4-9] (Table 1).

Charman et al. [5] described the first case of primary CNS angiosarcoma in an adult; a 65-year-old man, treated by surgical resection followed by radiation therapy, who survived for 13 months. Since this initial report, the hallmarks of CNS angiosarcoma are recognized as highly

\footnotetext{
* Correspondence: capalmer@uab.edu

${ }^{1}$ Division of Neuropathology, University of Alabama at Birmingham, PD6A

175, Birmingham, AL 35294, USA

2Department of Neurology, University of Alabama at Birmingham, FOT 1020, Birmingham, AL 35294, USA

Full list of author information is available at the end of the article
}

vascular malignant tumors with aggressive local recurrence and only modest response to chemotherapy or radiation treatment [10].

We report two cases of primary CNS angiosarcoma well characterized by imaging, histopathology, and immunohistochemistry. We discuss these cases in the context of similar cases reported within the last 35 years in an attempt to develop a rational approach to diagnosis and treatment, given the rarity of this entity.

\section{Case presentations}

\section{Patient 1}

A 35-year-old Caucasian woman presented to an outside facility with left eye irritation. Over the next six months, her symptoms progressed to exophthalmos with blurred vision. Imaging studies demonstrated an extra-axial homogeneous mass of the left retro-orbital infra-temporal area compressing the temporal lobe and displacing the left optic nerve. There was homogeneous enhancement of the mass following contrast administration (Figure 1). No adjacent cerebral edema was noted. Surgical resection was attempted, but was aborted after a subtotal resection due to hemorrhage. The pathological diagnosis was epithelioid angiosarcoma. Our patient was referred to the 
Table 1 Angiosarcoma of the brain in adults: case reports and series

\begin{tabular}{|c|c|c|c|c|c|}
\hline Series & Sex & Age & Location & Therapy & Survival \\
\hline Charman et al. [5] & M & 65 & Occipital & Surgery & 12 months \\
\hline Paulus et al. [3] & $M ; F$ & $24 ; 26$ & Temporal; frontal & Unknown & Unknown \\
\hline Mena et al. [1] & $\begin{array}{l}M(5), \\
F(3)\end{array}$ & $\begin{array}{l}2 \text { weeks to } 72 \text { years } \\
\text { (mean } 38 \text { years) }\end{array}$ & $\begin{array}{l}\text { Hemisphere (6), } \\
\text { meninges (1), } \\
\text { unknown (1) }\end{array}$ & Surgery & $\begin{array}{l}\text { Four months (4), } 30 \text { months (1), } \\
\text { alive } 39 \text { months (1), } \\
\text { alive } 102 \text { months (1), unknown (1) }\end{array}$ \\
\hline Cookston et al. [6] & $\mathrm{F}$ & 32 & Occipital & Surgery + RT & Alive three-and-a-half years \\
\hline Fuse et al. [7] & M & 39 & Parietal & Surgery + RT & 29 months \\
\hline Antoniadis et al. [4] & M & 41 & Parietal & Surgery + RT + chemotherapy & Alive 41 months \\
\hline Lach and Benoit [9] & M & 37 & Frontoparietal & Surgery & 18 months \\
\hline Merimsky et al. [2] & $M ; M$ & $27 ; 18$ & Parietal; occipitoparietal & Radiation only; surgery & $\begin{array}{l}\text { Two-and-a-half months; } \\
\text { five months }\end{array}$ \\
\hline
\end{tabular}

The study of Mena et al. includes two pediatric cases whose data are entangled with the adult cases. These two cases are not included in our discussion. $R T$ radiation therapy.

University of Alabama at Birmingham for completion of the resection following endovascular embolization of the tumor, which was completed eight months after her initial presentation. Intra-operative findings were significant for a well-capsulized lesion that could be dissected off the dura. No apparent intra-dural extension was noted. The embolization controlled the majority of the vascular supply, resulting in minimal blood loss. At her first postoperative visit, our patient reported improvement in all symptoms, including decreased proptosis, improved vision, and improved left facial numbness. At her latest visit one-and-a-half years after presentation, she was doing well, having completed six weeks of radiation therapy and concurrent bevacizumab. She continued a maintenance phase of bevacizumab for six months after radiation therapy. Her magnetic resonance imaging (MRI) scan remained stable when compared to prior scans.

\section{Patient 2}

A 47-year-old Caucasian man presented to our facility with acute onset of visual loss in the left eye of 10 days duration. There were also subtle memory problems and word-finding difficulties. Imaging studies demonstrated a large, heterogeneously-enhancing left sphenoid wing mass extending into the sphenoid sinus, thought to be either epidural or dura based and most consistent with meningioma (Figure 2), but with inhomogeneous enhancement and extension into the sphenoid sinus. Intra-operative findings were significant for a highly vascular tumor. Extensive bleeding was encountered until the tumor was removed. The margin of the neoplasm adjacent to the dura could be dissected off the dura without evidence of intra-dural extension. A neuropathological examination demonstrated a highgrade angiosarcoma. Post-operative imaging demonstrated a near-total gross resection, with only a small

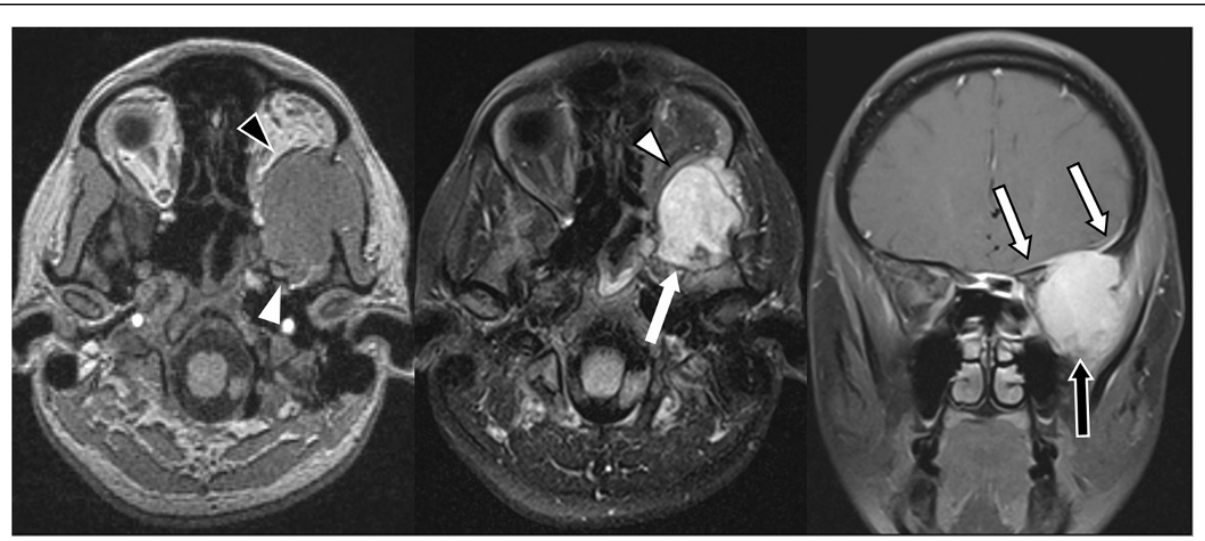

Figure 1 Axial unenhanced T1-weighted magnetic resonance image demonstrating a large mass in the left middle fossa (white arrowhead) extending through the left greater sphenoid wing into the left orbit (outlined black arrowhead). The fat-suppressed axial T1-weighted gadolinium-diethylenetriaminepentaacetic acid (Gd-DTPA)-enhanced image demonstrates the same findings (white arrow, outlined white arrowhead, respectively). The mass is enhanced homogeneously. The coronal fat-suppressed axial T1-weighted Gd-DTPA-enhanced image demonstrates the left middle fossa component (outlined black arrow) and extension up and over the margin of the left sphenoid ridge producing dural thickening and enhancement here (outlined white arrows). 
amount of enhancing tumor remaining in the sphenoid sinus adjacent to the carotid artery. Additional therapy is planned with radiation therapy, temozolomide, and bevacizumab.

Microscopic examination of our two cases demonstrate extensive areas of anastomosing vascular channels lined by atypical, plump endothelial cells with enlarged nuclei and prominent nucleoli. These cells are often present in multiple layers or papillary-like tufts projecting into the compressed lumen. Minimal stroma separates the abnormal vessels in these vascular areas (Figures 3 and 4). However, in other areas there are sparse vessels with abundant myxoid stroma within which there are scattered atypical spindle cells arranged singly or in small groups. This latter change was particularly prominent in our second patient's tumor. Both lesions included areas of hemorrhage and tumor necrosis.

Immunohistochemical staining for CD31 prominently decorates tumor cells, including the lining cells of the interconnected vascular channels and the spindle cells within the myxoid stroma (Figure 5).

\section{Discussion}

Accurate diagnosis of primary CNS angiosarcoma is greatly enhanced by the recognition of characteristic, though not always specific, features of clinical presentation, imaging characteristics, and histopathology. Usually there is rapid onset of neurological symptoms that relate to the tumor's location and rapidity of growth [1]. Imaging studies characteristically show a well-demarcated lesion of the cerebral hemisphere with avid enhancement following administration of intravenous contrast material such as gadolinium $[5,6]$. Although significant vasogenic edema has been reported in prior cases, neither of our patient's cases were associated with any cerebral edema. Histological examination demonstrates a malignant tumor with a range of differentiation that often includes

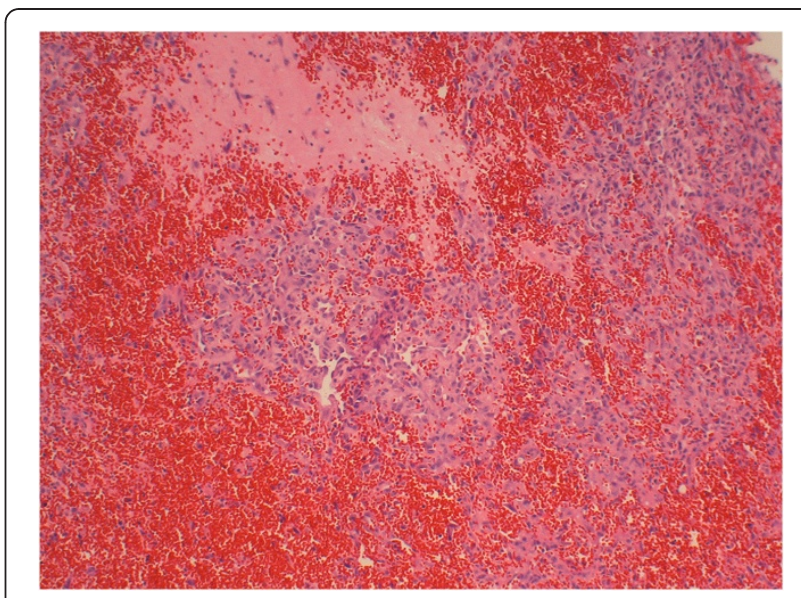

Figure $3 \mathrm{~A}$ low-power photomicrograph from the tumor removed from patient 1 revealing a vascular tumor with polygonal cells, spindle cells and abundant hemorrhage (hematoxylin and eosin stain, $\times 100$ ).

vascular channels lined by tufted or papillary aggregates of malignant endothelial cells, as well as poorlydifferentiated solid areas with malignant spindle cells residing within a collagenous or myxoid stroma [1]. Immunohistochemical staining with CD31, a sensitive and specific endothelial marker, is characteristically positive in both the well-differentiated vasoformative regions and in the less-differentiated solid areas of tumor.

In the cases reported over the last 25 years, primary angiosarcoma of the brain is characterized by a high rate of local recurrence and a short median survival time. In the series reported by Mena et al. [1], the median survival time in the five patients known to have died was eight months. However, two patients in that study were reported to be alive after follow-up intervals of 39 and 102 months, respectively. The one patient reported by Cookston et al. [6] was alive and doing well 42 months following diagnosis, having been treated by gross total

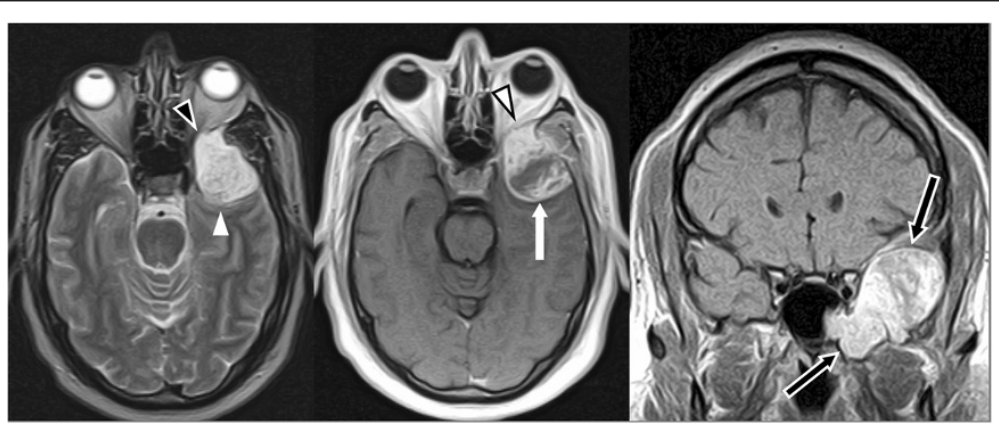

Figure 2 Axial T2-weighted magnetic resonance image demonstrating a mildly heterogeneously hyperintense mass extending from the left middle cranial fossa (white arrowhead) through the left greater sphenoid wing into the left orbit (outlined black arrowhead). The axial T1-weighted gadolinium-diethylenetriaminepentaacetic acid (Gd-DTPA)-enhanced image demonstrates identical findings (white arrow and outlined white arrowhead, respectively) and heterogeneous enhancement of the mass. The coronal T1-weighted Gd-DTPA-enhanced image demonstrates the mass extending downward and medially into the pterygoid recess of the left sphenoid sinus (outlined black arrows). 


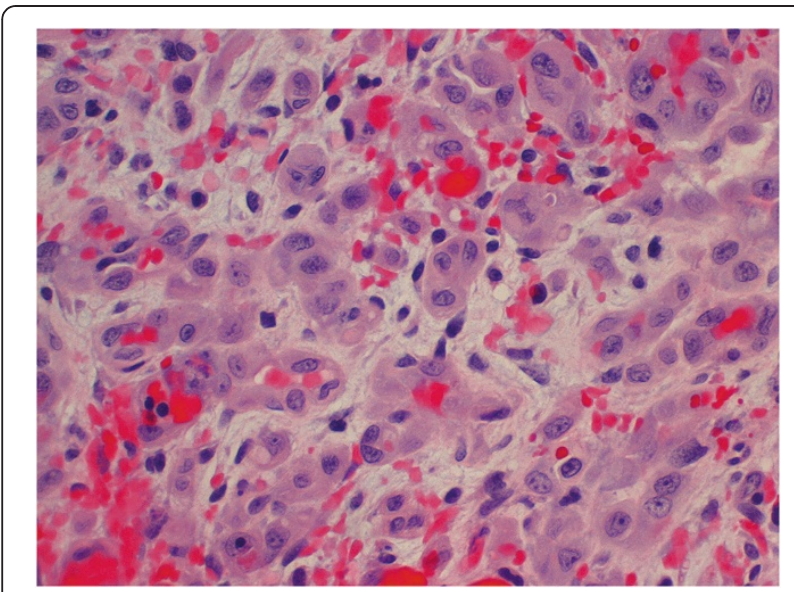

Figure $4 \mathrm{~A}$ high-power field of the angiosarcoma from patient 2 showing abortive vascular structures (hematoxylin and eosin stain, $\times 400)$.

resection and adjuvant radiation therapy. While primary therapy is surgical, a few patients, such as this one, have apparently benefited from radiation therapy and/or chemotherapy (Figure 6), either in the adjuvant setting or as a later addition at the time of recurrence.

Chemotherapy for primary CNS angiosarcoma, as for virtually all soft tissue sarcomas, is problematic. Combination chemotherapy has not been shown to be any more effective than single agent therapy in most instances [11]. Temozolomide has shown promising activity against sarcomas in general [11]; it is an option for CNS disease because it crosses the blood brain barrier. For most histological types of sarcoma, single agent therapy with doxorubicin is favored because of its beneficial profile of progression-free survival and relatively tolerable toxicity [10]. Regardless, its use is palliative rather than curative. Paclitaxel has been shown to

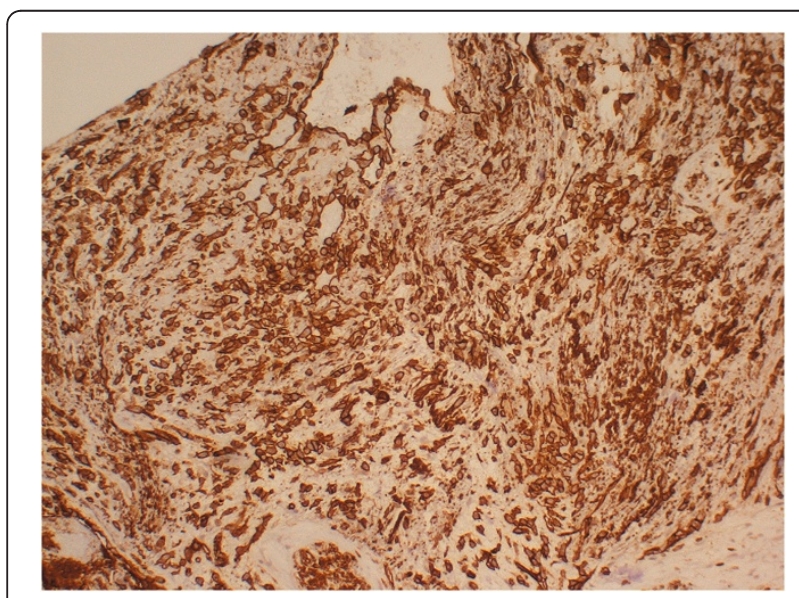

Figure 5 Both tumors were positive for $\mathrm{CD} 31$ in the polygonal and spindle cells (CD31 immunoperoxidase stain, $\times 100)$.

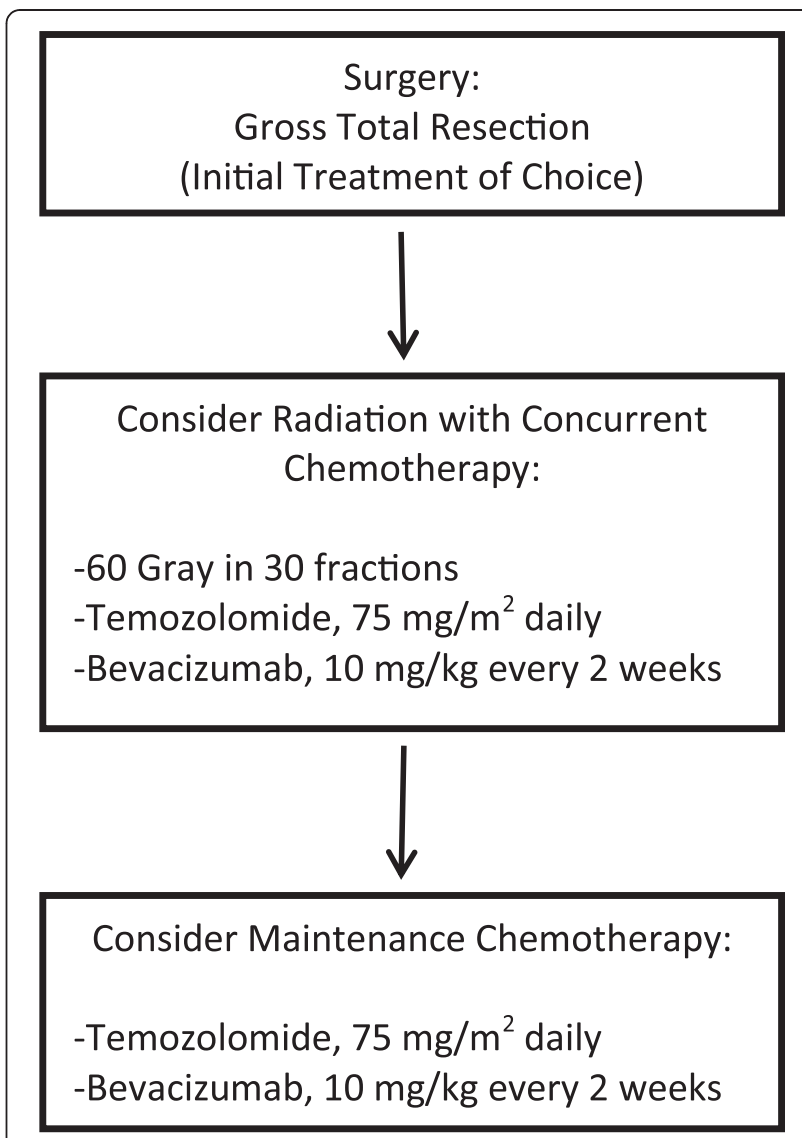

Figure 6 A proposed flow chart for the treatment of intra-cranial angiosarcoma.

produce favorable progression-free survival rates at three and six months in both chemonaive and previouslytreated patients with the diagnosis of soft tissue angiosarcoma in Phase II clinical trials [12]. Schlemmer et al. [13] report a response rate of $62 \%$ for paclitaxel in the setting of advanced angiosarcoma of soft tissue. However, the use of paclitaxel or other chemotherapeutic agents has not yet been reported in primary CNS angiosarcoma.

Bevacizumab, a vascular endothelium growth factor (VEGF) inhibitor, has been used with some success in recurrent glioblastoma, a primary CNS tumor that is known to produce VEGF [14]. The use of bevacizumab for primary CNS angiosarcoma has not been reported, although a phase II trial looking at bevacizumab in patients with unresectable soft tissue angiosarcoma is ongoing (NCT00288015). Preliminary results from the first 27 patients in this trial have been briefly reported by Park et al. [15]. Median progression-free survival was 12 weeks. These authors also discuss data suggesting that combining temozolomide with bevacizumab may result in a potentiation of the latter's anti-angiogenic effect.

In addition, two multicenter phase II clinical trials are currently in recruitment to look at paclitaxel and 
bevacizumab in the treatment of metastatic or unresectable visceral or soft tissue angiosarcoma (NCT01055028 and NCT01303497). These studies do not address primary CNS angiosarcoma; in fact, known CNS disease is an exclusion criterion.

\section{Conclusions}

The rarity of primary angiosarcoma of the brain and the resulting paucity of relevant studies and case reports precludes a definitive judgment concerning optimal therapy. Regardless, suggestions derived from the few published cases, along with the short follow-up from our two more recent cases, may allow the preliminary formulation of a potentially effective treatment plan using modern, multimodality therapy. Surgery with or without tumor embolization, with the goal of gross total resection, remains the standard of care. Post-operative adjuvant radiation therapy may provide a benefit, particularly in cases where gross total resection is not possible. There may be a rationale for using anti-angiogenesis agents such as bevacizumab, perhaps in combination with temozolomide for synergistic anti-angiogenic effect. Finally, treatment results for paclitaxel in soft tissue angiosarcoma suggest that there may also be a role for this chemotherapeutic agent in primary CNS angiosarcoma.

\section{Consent}

Written informed consent was obtained from both patients for publication of this manuscript and any accompanying images. A copy of the written consent is available for review by the Editor-in-Chief of this journal.

\section{Competing interests}

The authors declare that they have no competing interests.

\section{Authors' contributions}

$\mathrm{JRH}$ drafted the manuscript; CAP provided the neuropathology and participated in the final draft; KOR was responsible for the neurosurgical care of both our patients; JKC provided the neuroradiology interpretations for both our patients as well as this section in the manuscript; HMFS was responsible for one of our patient's chemotherapeutic regimens and helped to draft the manuscript; LBN conceived the study, was responsible for one of our patient's chemotherapeutic regimens and helped to draft the manuscript. All authors read and approved the final manuscript.

\section{Acknowledgments}

An abbreviated form of this manuscript was presented at the 16th Annual Society for NeuroOncology Meeting in Orange County, California, November 2011.

\section{Author details}

${ }^{1}$ Division of Neuropathology, University of Alabama at Birmingham, PD6A 175, Birmingham, AL 35294, USA. ²Department of Neurology, University of Alabama at Birmingham, FOT 1020, Birmingham, AL 35294, USA. ${ }^{3}$ Division of Neurosurgery, University of Alabama at Birmingham, FOT 1046, Birmingham, AL, 35294, USA. ${ }^{4}$ Department of Radiology, University of Alabama at Birmingham, JT N418, Birmingham, AL 35294, USA.

Received: 10 August 2011 Accepted: 2 March 2012

Published: 21 August 2012

\section{References}

1. Mena H, Ribas JL, Enzinger FM, Parisi JE: Primary angiosarcoma of the central nervous system. J Neurosurg 1991, 75:73-76.

2. Merimsky O, Lepechous C, Terrier P, Vanel D, Delord JP, LeCesne A: Primary sarcomas of the central nervous system. Oncology 2000, 58:210-214.

3. Paulus $W$, Slowik $F$, Jellinger $K$ : Primary intracranial sarcomas: Histopathological features of 19 cases. Histopathol 1991, 18:395-402.

4. Antoniadis C, Selviaridis P, Zaramboukas T, Fountzilas G: Primary angiosarcoma of the brain: case report. Neurosurg 1996, 38:583-586.

5. Charman HP, Lowenstein DH, Cho KG, DeArmond SJ, Wilson CB: Primary cerebral angiosarcoma. J Neurosurg 1988, 68:806-810.

6. Cookston M, Cotter GW, Schlitt M, Bastian FD: Primary angiosarcoma of the brain. South Med J 1991, 84:517-520.

7. Fuse T, Takagi T, Hirose M: Primary intracranial epithelioid angiosarcoma. Neurol Med Chir (Tokyo) 1995, 35:364-368.

8. Muhlau M, Schlegel J, von Einsiedel HG, Conrad B, Sander D: Multiple progressive intracerebral hemorrhages due to an angiosarcoma: a case report. Eur J Neurol 2003, 10:741-742

9. Lach B, Benoit BG: Primary composite angiogenic leiomyosarcomaepitheloid angiosarcoma of the brain. Ultrastruct Pathol 2000, 24:339-346.

10. Grimer R, Judson I, Peake D, Seddon B: Guidelines for the management of soft tissue sarcomas. Sarcoma 2010, 2010:1-15.

11. Penel N, Van Glabbeke M, Marreaud S, Ouali M, Blay JY, Hohenberger P: Testing new regimens in patients with advanced soft tissue sarcoma: analysis of publications from the last 10 years. Ann Oncol 2011, 22:1266-1272.

12. Penel N, Bui BN, Bay JO, Cupissol D, Ray-Coquard I, Piperno-Neumann S, Kerbrat $P$, Fournier $C$, Taieb $S$, Jimenez $M$, Isambert N, Peyrade $F$, Chevreau C, Bompas E, Brain EG, Blay JY: Phase II trial of weekly paclitaxel for unresectable angiosarcoma: the ANGIOTAX study. J Clin Oncol 2008, 26:5269-5274.

13. Schlemmer M, Reichardt P, Verweij J, Hartmann JT, Judson I, Thyss A, Hogendoorn PC, Marreaud S, Van Glabbeke M, Blay JY: Paclitaxel in patients with advanced angiosarcomas of soft tissue: a retrospective study of the EORTC soft tissue and bone sarcoma group. Eur J Cancer 2008, 44:2346-2433.

14. Friedman HS, Prados MD, Wen PY, Mikkelsen T, Schiff D, Abrey LE, Yung WK, Paleologos N, Nicholas MK, Jensen R, Vredenburgh J, Huang J, Zheng M, Cloughesy T: Bevacizumab alone and in combination with irinotecan in recurrent glioblastoma. J Clin Oncol 2009, 27:4733-4740.

15. Park MS, Ravi V, Araujo DM: Inhibiting the VEGF-VEGFR pathway in angiosarcoma, epithelioid hemangioendothelioma, and hemangiopericytoma/solitary fibrous tumor. Curr Opin Oncol 2010, 22:351-355.

doi:10.1186/1752-1947-6-251

Cite this article as: Hackney et al:: Primary central nervous system angiosarcoma: two case reports. Journal of Medical Case Reports 2012 6:251.

\section{Submit your next manuscript to BioMed Central and take full advantage of:}

- Convenient online submission

- Thorough peer review

- No space constraints or color figure charges

- Immediate publication on acceptance

- Inclusion in PubMed, CAS, Scopus and Google Scholar

- Research which is freely available for redistribution 